\title{
Free and DNA Adducted Aflatoxins in Chronic Liver Diseases that Predispose Patients to Hepatocellular Carcinoma in Mexico
}

\section{Alvarez-Banuelos $\mathbf{M T}^{1}$, Carvajal-Moreno $\mathbf{M}^{1 *}$, Mendez-Ramirez $\mathrm{I}^{2}$ and Rojo-Callejas $\mathrm{F}^{3}$}

${ }^{1}$ Department of Botany, Institute of Biology, National Autonomous University of Mexico (UNAM), Ciudad Universitaria, Coyoacan, Mexico

${ }^{2}$ Department of Probability and Statistics, Institute of Research in Applied Mathematics and Systems, National Autonomous University of Mexico (UNAM), Mexico

${ }^{3}$ Department of Analytical Chemistry, Faculty of Chemistry, National Autonomous University of Mexico (UNAM), Mexico

\begin{abstract}
Aflatoxins are mutagenic hepatocarcinogenic fungal metabolites that contribute to chronic hepatitis B and C and viral cirrhosis, which can both evolve into hepatocellular carcinoma.
\end{abstract}

Objective: To identify and quantify free aflatoxins and $A F B_{1}-N^{7}$-guanine ( $A F B_{1}-N^{7}$-Gua) adducts (active carcinogen) in the urine of Mexican patients with chronic liver diseases.

Methods: Urine samples from 210 Mexican patients with chronic liver diseases, hepatitis B or C, or viral cirrhosis and four control groups: 1) patients with alcoholic cirrhosis, 2) patients with no hepatic diseases, 3) patients with kidney failure, and 4 ) healthy persons, were analyzed for free aflatoxins and $\mathrm{AFB}_{1}-\mathrm{N}^{7}$-Gua adducts by Inhibitory Indirect ELISA and high performance liquid chromatography, and both methods produced similar results $\left(R^{2}=0.90\right)$. A questionnaire regarding foods with high risk of containing aflatoxins was applied to relate diet and disease.

Results: Aflatoxin-positive samples were found from patients in the following groups: hepatitis B $(50 \%)$, viral cirrhosis $(26 \%)$, hepatitis $C(16.6 \%)$, alcoholic cirrhosis $(10 \%)$, healthy $(10 \%)$, kidney failure $(0.47 \%)$, and chronic nonhepatic diseases $(0 \%)$, with $\mathrm{R}^{2}=0.95$. Risk groups had more $A F B_{1}-\mathrm{N}^{7}-\mathrm{Gua}$ adducts than controls. High performance liquid chromatography identified free $A F B_{1}$ (exposure), types $M_{1}$ and $P_{1}$ (detoxification metabolites), and Inhibitory Indirect ELISA quantified $\mathrm{AFB}_{1}-\mathrm{N}^{7}-$ Gua adduct (a DNA repair biomarker)

High-risk foods related $(P \leq 0.001)$ to hepatic diseases were maize, oil seeds, and dairy products.

Conclusion: Mexican patients with chronic liver diseases exhibited high concentrations of aflatoxins and Aflatoxin- $\mathrm{N}^{7}-\mathrm{Gua}$ adducts, both of which showed high exposure and the last are significant biomarkers for the risk of liver diseases that predispose patients to liver cancer

Keywords: Aflatoxins; AF-N $\mathrm{N}^{7}$-Gua adducts; Hepatitis; Cirrhosis; Hepatic diseases

Abbreviations: $\mathrm{AC}$ : Alcoholic Cirrhosis; $\mathrm{AFB}_{1}$ Aflatoxin $\mathrm{B}_{1}$; $\mathrm{AFB}_{1}-$ FAPY adduct: $\mathrm{AFB}_{1}$-formamido Pyrimidine; AFB1-N7-Gua adduct: $\mathrm{AFB}_{1}-\mathrm{N}^{7}$-guanine Adduct; $\mathrm{AFM}_{1}$ Aflatoxin $\mathrm{M}_{1} ; \mathrm{AFP}_{1:}$ Aflatoxin $\mathrm{P}_{1}$; $\mathrm{AFs}$ : Aflatoxins; BSA: Bovine Serum Albumin; c.os.s. = cereals, oil seeds and spices; CII ELISA: Competitive Inhibitory Indirect ELISA; CNHD: Chronic Non Hepatic Diseases; cr: creatinine; CV \%: Coefficient of Variation Percentage; CV: Standard Coefficient of Variation; ELISA: Enzyme-Linked Immunosorbent Assay; H: Healthy; HBV: Hepatitis B virus; HCC: Hepatocellular carcinoma; HCV: Hepatitis C virus; HPLC: High performance liquid chromatography; IA: Total Anti-AF Immunoaffinity Columns; Inhib\%: Inhibition Percentage; KF: Kidney Failure; LOD: Limit of Detection; LOQ: Limit of Quantification; Monoclonal $\mathrm{AFB}_{1}$-BSA conjugate: Aflatoxin $\mathrm{B}_{1}$ - Bovine Serum Albumin Conjugate; $\mathrm{R}^{2}$ : Correlation Coefficient; SD: Standard Deviations; TMB: 3,30-,5,50-tetramethylbenzidine; UV abs: Ultraviolet Absorption; VC: Viral Cirrhosis

\section{Introduction}

Aflatoxins (AFs) are secondary metabolites and polyketides of a group of dihydrobisfuran-coumarins, which are divided into two subgroups depending on their chemical structure. The bisfurancoumarin-cyclopentanones include AFs, which are further categorized into groups labeled $\mathrm{B}, \mathrm{Q}, \mathrm{P}$ and $\mathrm{M}\left(\mathrm{AFB}_{1}, \mathrm{AFB}_{2}, \mathrm{AFB}_{2 \mathrm{a}}, \mathrm{AFM}_{1}, \mathrm{AFM}_{2}\right.$, $\mathrm{AFM}_{2 \mathrm{a}} \mathrm{AFQ}_{1}, \mathrm{AFP}_{1}$ ), and aflatoxicol (AFL), which corresponds to the subgroup of bisfuran-coumarin-lactones, in which the AFs in the $G$ groups $\mathrm{G}\left(\mathrm{AFG}_{1}, \mathrm{AFG}_{2}, \mathrm{AFG}_{2 \mathrm{a}}\right)$ are placed [1-3].
AFs are produced primarily by the fungi Aspergillus flavus Link, A. parasiticus Speare, and A. nomius Kurtzman [4] and contaminate many foods worldwide [5]. Other fungi have been reported to be AF producers: A. tamarii [6], A. arachidicola, A. bombycis, A. minisclerotigenes, A. ochraceoroseus, A. pseudotamarii, A. rambellii, and Emericella venezuelensis [7,8]. Other fungi reported to produce AFs [9] (A. tamarii, A. oryzae, A. versicolor, Penicillium commune, $P$. griseofulvum) have been proven to be misidentified.

AFs are the most toxic of the known mycotoxins and are a significant risk factor for liver and kidney cancer [10]. These potent mutagens and carcinogens [11] are directly implicated in causing or exacerbating liver diseases such as hepatitis B (HBV) [12] and C (HCV) [13], cirrhosis [14,15], various cancers [11,16,17], and primary Hepatocellular Carcinoma (HCC) $[18,19]$, as well as teratogenicity [20], undernutrition, micronutrient malabsorption [10], immune dysfunction [21,22], stunting [23] and protein deficiency syndromes

*Corresponding author: Carvajal-Moreno M, Department of Botany, Institute of Biology, National Autonomous University of Mexico (UNAM), Ciudad Universitaria, Coyoacan, Mexico, Tel: (5255)-5622-9138; Fax: (5255)-5550-1760; E-mail: magdac@ib.unam.mx

Received June 30, 2015; Accepted August 21, 2015; Published August 24, 2015

Citation: Alvarez-Banuelos MT, Carvajal-Moreno M, Mendez-Ramirez I, RojoCallejas F (2015) Free and DNA Adducted Aflatoxins in Chronic Liver Diseases that Predispose Patients to Hepatocellular Carcinoma in Mexico. J Cancer Sci Ther 7: 274-282. doi:10.4172/1948-5956.1000363

Copyright: (c) 2015 Alvarez-Banuelos MT, et al. This is an open-access article distributed under the terms of the Creative Commons Attribution License, which permits unrestricted use, distribution, and reproduction in any medium, provided the original author and source are credited. 
[24]. The immunosuppressive effect of $\mathrm{AFB}_{1}$ in humans has been demonstrated; when human lymphocytes are exposed to $\mathrm{AFB}_{1}$, they exhibit impaired cellular respiration, provoking necrosis [25].

Global diet differences may lead to heterogeneity in AF-induced morbidity. Although such data would represent a crucial resource for managing food-borne AF risk, data are lacking from many parts of the world.

Mexico is an area with a diet particularly high in AFs and extraordinarily high instances of liver disease. Maize, the dietary staple food in Mexico, has among the highest levels of AFs of all grains [26]. In 2003, hepatic cirrhosis, chronic liver diseases and HCC were the second cause of death among Mexicans of working age (15-64 years), second only to cardiovascular diseases, and representing one of the highest such rates worldwide. In 2013, the fourth cause of mortality in Mexico was liver cirrhosis, with 29,335 deaths [15,27,28]. Despite this exceptionally high incidence of liver disease, little attention has been given to AF levels in foods, tissues or fluids of patients in Mexico [15].

AFs provide an effective system to understand the relationship between diet and disease because they are readily detected in tissues and fluids. Oxidation of $\mathrm{AFB}_{1}$ links it covalently to DNA, forming adducts that can produce point mutations, activate proto-oncogene to oncogene transformation and initiate the carcinogenic process [29]. $\mathrm{AFs}$ covalently bind to albumin, forming $\mathrm{AFB}_{1}$-albumin adducts, and to DNA, forming aflatoxin-DNA adducts, which primarily exist as 8,9-dihydroxy-8- $\left(\mathrm{N}^{7}\right)$ guanyl-9-hydroxy $\mathrm{AFB}$ adducts $\left(\mathrm{AFB}_{1}-\mathrm{N}^{7}-\mathrm{Gua}\right)$ [30]. These adducts are converted to two secondary lesions: an apurinic site and the $\mathrm{AFB}_{1}$-formamido pyrimidine $\left(\mathrm{AFB}_{1}-\mathrm{FAPY}\right)$ adduct, which is primarily responsible for the genotoxic, mutagenic and carcinogenic properties of $\mathrm{AFB}_{1}$ [31]. These adducts are valuable biomarkers for hepatic diseases, such as hepatitis B [32], hepatitis C [13], and HCC [33].

Dietary information from patients with chronic liver diseases and various control groups, along with AF urine levels, were collected, and the data support the hypothesis that high dietary AF levels correlate with chronic liver diseases

\section{Methods}

\section{Sampling design and patient selection criteria}

Seven groups were studied, each with 30 individuals totaled 210 cases (109 women and 101 men aged 26 to 74 ) that originated from the National Institute of Medical Sciences and Nutrition "Salvador Zubirán" (Instituto Nacional de Ciencias Médicas y de la Nutrición "Salvador Zubirán"), and the patient pool also contained 12 hepatitis B cases from the National Medical Center "The Race" (Centro Médico Nacional "La Raza”), both in Mexico City.

The selection criteria for the three risk groups of patients were

1. For chronic HBV and HCV: histopathology, presence of the HBsAgpositive marker for HBV or positive result with anti-HCV marker, and abnormal biochemical tests.

2. For post-viral hepatic cirrhosis (VC): histopathology and abnormal hepatic functions and biochemical test results.

The selection criteria for control groups of patients were

1. Alcoholism: history of chronic alcoholism, histopathology of alcoholic cirrhosis, abnormal hepatic function, and negative HBV and HCV markers.

2. Chronic or terminal kidney failure (urea and creatinine tests), blood or chronic peritoneal dialysis substitution, and negative viral markers.

3. Chronic non-hepatic diseases (CNHD) or gastric ulcers.

4. Healthy individuals: normal hepatic functions and serological test.

The sample size was the minimum size to ensure that the sample mean exhibited an approximately normal sampling distribution. Sex and age ranges of the risk and control groups are shown in Table 1.

\section{Collection and urine sample analysis}

This study focused on collecting $\mathrm{AFB}_{1}-\mathrm{N}^{7}$-Gua adducts in urine because this method is non-invasive and because chronic liver diseases are not treated through surgical operations in which samples could be collected; therefore, the collection of sampling tissues is possible only by biopsies and necropsies, and urine is easier to obtain. Each patient answered 200 questions about their diet, which were developed by the Dept. of Epidemiology of the Institute of Medical Sciences and Nutrition, and provided a 24-hour urine sample that was measured and homogenized by vortexing; an aliquot of urine was removed for colorimetric determination. To adjust urine concentrations and make comparable samples, creatinine (cr) test kits were applied to calculate the rate of excretion ( $\mathrm{mg} \mathrm{AF} / \mathrm{cr} \mathrm{mg}$ ) in order to establish kidney function. The remaining urine was adjusted to $5.0 \mathrm{pH}$, and $25 \mathrm{~mL}$ of the urine was concentrated through Sep-Pak $\mathrm{C}_{18}$ activated columns, purified with total $\mathrm{AF}$ immunoaffinity columns, eluted with $1.5 \mathrm{~mL}$ of methanol, dried and re-dissolved in PBS to recover the original urine concentration per case. Each sample, with 3 replicates, was filtered through $1 \mu \mathrm{m}$ Millipore membranes. Reverse-phase High-Performance Liquid Chromatography (HPLC) was used to verify the purity and to quantify the reference standards and the free and adducted $\mathrm{AF}$ urine samples with $\mathrm{AFB}_{1}$, the hydroxylates $\mathrm{AFM}_{1}$ and $\mathrm{AFP}_{1}$ and $\mathrm{AFB}_{1}-\mathrm{N}^{7}$ Gua adducts by standard methods $[34,35]$. The HPLC used a pump system with a injector adapted to a $20 \mathrm{~mL}$ loop, a data integrator, a spectrophotometer at an absorbance of $360 \mathrm{~nm}$ (excitation $360 \mathrm{~nm}$, emission $450 \mathrm{~nm}$ ), and a fluorescence detector. An HPLC reversephase $\mathrm{C} 18$ column $(25 \times 0.460 \mathrm{~cm})$ adapted with a pre-column was used.

All solvents were HPLC purity grade and were degasified with a flask adapted to a vacuum pump. The mobile phase was an isocratic solution of methanol/distilled $\mathrm{H}_{2} \mathrm{O}(60: 40 \mathrm{v} / \mathrm{v})$ mixture filtered over microfiltration membranes $(0.2-\mathrm{mm}$ pore size) at a flow rate of $1 \mathrm{~mL} /$ $\min$

\section{Conjugates and $A F B_{1}-\mathrm{N}^{7}-\mathrm{Gua}$ adduct in vitro synthesis}

Monoclonal $\mathrm{AFB}_{1}-\mathrm{BSA}$ conjugates recognized eight types of $\mathrm{AFs}$ as well as the $A F B_{1}-\mathrm{N}^{7}-\mathrm{Gua}$ adduct. Two preparations of the antiaflatoxin monoclonal $\mathrm{AFB}_{1}-\mathrm{BSA}\left(\mathrm{AFB}_{1}-\mathrm{BSA}\right)$ conjugate were tested: 6E9 purified with Sephadex and from tissue culture, each with six concentrations $(1: 100,1: 200,1: 300,1: 500,1: 1000$ and 1:1500) and six replicates.

$\mathrm{AFB}_{1}-\mathrm{N}^{7}$-Gua synthesis was performed as a control standard for ELISA $[16,36,37]$. To test the purity of the $\mathrm{AFB}_{1}-\mathrm{N}^{7}$-Gua adduct, electrophoresis was performed using a $1 \%$ agarose gel with Tris-acetate and ethidium bromide buffer. As a standard, lymphocyte DNA and different concentrations of AF-adducted DNA were applied with phenolbromine at 100 volts for $35 \mathrm{~min}$. Bands were visualized with a 
transilluminator. Total anti-AF immunoaffinity columns were used to concentrate free $\mathrm{AFB}_{1}, \mathrm{AFB}_{1}-\mathrm{N}^{7}$-Gua adducts, and $\mathrm{AFM}_{1}$ and $\mathrm{AFP}$ hydroxylates.

\section{$\mathrm{AFB}_{1}$ - chloride-Ovalbumin ( $\left.\mathrm{AFB}_{1}-\mathrm{Ov}\right)$ conjugate synthesis}

ELISA plates were coated with $\mathrm{AFB}_{1}-\mathrm{Ov}$ conjugate and incubated overnight. To obtain a stock concentration of $50 \mathrm{mg} / \mathrm{mL}$, each new synthesized batch of $\mathrm{AFB}_{1}-\mathrm{Ov}$ conjugate was tested by preparing seven dilutions $(2.5,5,10,20,30,40$ and $50 \mathrm{ng})$ with six replicates each. $\mathrm{AFB}_{1}-$ Ov conjugate and $\mathrm{AFB}_{1}-\mathrm{N}^{7}$-Gua adducts were obtained using standard methodology [16,34-36].

$\mathrm{AFB}_{1}$ was dissolved in dichloromethane (DCM) and gaseous chloride linked to an $\mathrm{AFB}_{1}-\mathrm{Cl}-\mathrm{DCM}$ conjugate; $\mathrm{DCM}$ was eliminated by roto-evaporation, leaving behind the $\mathrm{AFB}_{1}-\mathrm{Cl}$. Dimethylsulfoxide, ovalbumin and $\mathrm{NaOH}(5 \mathrm{M})$ were added to form the $\mathrm{AFB}_{1}-\mathrm{Cl}-$ Ov conjugate. To ensure the quality of the synthesis, thin layer chromatography was performed at different times, producing an efficiency level of $90 \%$ and a concentration of $1.5 \mathrm{mg} / \mathrm{mL}$.

\section{Anti-mouse IgG peroxidase conjugate (a-mouse)}

To determine the best concentration for the competitive indirect inhibitory (CII) ELISA test, six dilutions (1:400, 1:500, 1:600, 1:800, $1: 1000$ and $1: 1500)$ of $\alpha$-mouse IgG peroxidase antibody conjugate were tested, each with six replicates.

The $\mathrm{AFB}_{1}-\mathrm{N}^{7}$-Gua adduct was synthesized in vitro using standard methodology $[29,36,38]$ and was modified [16] to use it as an ELISA test reference standard. It was obtained in a high-risk laboratory with all possible precautionary measures taken to avoid fatal accidents. The purity of the adduct was determined by electrophoresis $[34,38,39]$.

\section{Aflatoxin competitive indirect inhibition ELISA method}

Validation of CII ELISA method was necessary to evaluate the characteristics, quality parameters and the precision of the system [40-43], including the following parameters: the standard deviation (SD), the coefficient of variation ( $\mathrm{CV} \%$ ), the intra- and inter-assay, the repeatability, the linearity of the method and of the system (calibration curves), the detection and quantification limits [44], the accuracy and the repeatability of the method $[41,44]$, the recovery percentage $[44,45]$ and the recovery percentage limits $[34,35]$.

The limit of detection (LOD) was $0.1 \mathrm{pg} / \mathrm{mg}$ DNA, and the Limit of Quantification (LOQ) was $10 \mathrm{pg} / \mathrm{mg}$ DNA; these limits were of adequate sensitivity for the AF assay. In addition, recovery reached nearly $100 \%$. The linearity of the system (calibration curves) was measured, and the standard curves of $\mathrm{AFB}_{1}$ and $\mathrm{AFB}_{1}-\mathrm{N}^{7}$-Gua adduct with eight dilutions $\left(0.1,1,10,100,1000,1 \times 10^{4}, 1 \times 10^{5}, 1 \times 10^{6} \mathrm{pg} / \mathrm{mg}\right)$ were run with three replicates to establish the CII ELISA UV absorption curve, the correlation coefficient $\left(\mathrm{R}^{2}\right)$, and the values of the ordinate to origin and the slope. The linear regression was calculated and the curves were plotted with Excel software.

\section{Stock solution, type of plate and coating evaluation}

To prepare a stock solution of $1 \mathrm{mg} / \mathrm{mL} \mathrm{AFB}_{1}$, which was used as a standard in CII ELISA or to synthesize the $\mathrm{AFB}_{1}-\mathrm{N}^{7}$-Gua adduct, the molecular weight and molar extinction coefficient were used following a known method (970.44 (A)) [46]. To optimize the system, five different ELISA plates with $\mathrm{AFB}_{1}-\mathrm{Cl}-\mathrm{Ov}$ adduct optimal coating were simultaneously tested: Flow Laboratories, Inc., Corning Costar plates (low and high adherence), Nunc polysorp (tissue culture) and Maxisorp of different adherence. All plates were tested with the same reactives, conditions of incubation and washing, and they were stored at $4^{\circ} \mathrm{C}$ [34]. A cross titering of $\mathrm{AFB}_{1}$-Bovine Serum Albumin ( $\mathrm{AFB}_{1}$ $\mathrm{BSA}$ ) and second-mouse conjugate coupled with peroxidase was performed to select the highest concentration signal of $1 \times 10^{6} \mathrm{pg} / \mathrm{mg}$ of the AF antigen.

Tests were performed to evaluate the quality of the system within the international accepted parameters of minimum detectable concentration, accuracy, precision, recovery limits and coefficient of variation.

Levels and purity tests of each aflatoxin and adduct by HPLC were performed. Individual standard curves with 5 dilutions $(4,8,12,16$, $20 \mu \mathrm{g} / \mathrm{L}$ ) for each AF were run to establish retention times, and the linear regression was calculated with Excel software. ELISA conditions were $10 \mathrm{ng} /$ well of ovalbumin-AF adduct for coating, anti-mouse IgG peroxidase conjugate antibody dilution (1:1000), anti-AF monoclonal dilution $(1: 300)$ and $3,3^{\prime}, 5,5^{\prime}$ tetramethyl benzidine to dye the reaction. Absorbance $(450 \mathrm{~nm})$ was registered in an ELISA automatic plate reader, and a plate washer was also used. Averages, standard deviations, coefficients of variation and an accepted minimum of $80 \%$ of inhibition were calculated $[16,35]$.

\section{Aflatoxin Competitive Indirect Inhibition ELISA (CII ELISA)}

The CII ELISA test was used to quantify the $\mathrm{AFB}_{1}$ and $\mathrm{AFB}_{1}-\mathrm{N}^{7}$-Gua adducts in the samples by comparing the standard curve inhibition of the adducts following known methodology $[16,35]$. The ELISA's selectivity increased with the concentration of anti-aflatoxin monoclonal $\mathrm{AFB}_{1}$ BSA conjugate, as well as the total anti-AF immunoaffinity columns (IA), which extract concentrations of different AFs, AF hydroxylates and $\mathrm{AFB}_{1}$-DNA adducts from samples, as certified in our laboratory and in previous research laboratories $[47,48]$. Included on all plates as negative controls were the following: triplicate wells of blank samples diluted in buffer B only, unadducted BSA and calf thymus DNA, to account for any nonspecific inhibition, and the enzyme substrate color indicator 3, 30-, 5, 50-tetramethylbenzidine (TMB); sulfuric acid was used to stop the reaction and an ELISA plate Multiwash and ELISA automatic plate reader were used to obtain the inhibition percentage. The automatic ELISA plate reader provided media absorbances, from which the standard deviations of each well from the standard coefficient of variation (CV) and inhibition percentage (Inhib \%) were calculated. If the $\mathrm{CV}$ was higher than $10 \%$, the sample measurement was repeated.

\section{Food survey questionnaire}

The 200 questions provided to each of the 210 patients in this study were chosen by the Departments of Epidemiology of Social Health and of Nutrition, which designed the food questionnaire; both departments are located at the National Institute of Nutrition Sciences "Salvador Zuribán”.

The food survey questionnaire was based on the information provided by the patients; no food was analyzed for AF contamination. The types of food considered in the questionnaire were those considered at risk for AF contamination [47].

The risk foods were grouped as cereals, oil seeds, spices, dairy products, meats, alcoholic fermented beverages and their derivatives, and sauces.

The number of ingested rations, types of food susceptible to AF contamination, and the diet during the 24 to 48 hours prior to urine sampling, were summarized weekly, monthly and annually in the 
applied questionnaire and were based on the information provided by the patients in the questionnaire. No food was weighed, nor was food intake measured.

These data were checked against a total of 42,000 reported ingested foods with a risk of AF contamination, based on a questionnaire including approximately 200 different foods and the amount of reported ingested amounts by the monitored patients.

\section{Statistical analysis}

The data set was assembled using Fox Plus and Excel and was analyzed with the JMP and SAS (Statistical Analysis System) packages.

The dependent variables (consumption per food and AFlogarithm) had nearly normal distributions. Analysis of variance was used to evaluate whether AF-log media changed between groups of disease. The Box-Cox transformation was applied to some variables and the Kruskall-Wallis test was used for non-normal data. A Tukey test was applied to significant differences in the $\mathrm{F}$ test. These analyses included the seven groups of diseases and controls and another analysis excluding alcoholics.

Cluster analysis was used to analyze types of food consumption (eliminating alcohol) represented as categorical variables, followed by correspondence and discriminant analyses (canonical correlation) of viral hepatic diseases with the healthy control group to evaluate the association between food consumption and diseases [39].

Only positive tests of free $\mathrm{AFB}_{1}, \mathrm{AFM}_{1}, \mathrm{AFP}_{1}$ and $\mathrm{AFB}_{1}-\mathrm{N}^{7}-\mathrm{Gua}$ adduct in urine were statistically analyzed. For these variables, analysis of contrasts showed differences between healthy control and groups at risk and between viral diseases and alcoholic cirrhosis.

In addition, a univariate analysis of variance, contrasts, and ANOVA tests were applied to consumption of food as a dependent variable.

\section{Results}

\section{$\mathrm{FB}_{1}-\mathrm{N}^{7}$-Gua adducts in vitro synthesis}

The carcinogen $\mathrm{AFB}_{1}-\mathrm{N}^{7}$-Gua adduct was synthesized in vitro to be used as a standard in the CII ELISA test; the chromatographic peak appeared at a retention time of $22.4 \mathrm{~min}$, and a concentration of 2.1 $\mathrm{mg} / \mathrm{mL}$ was obtained (Figure 1 ).

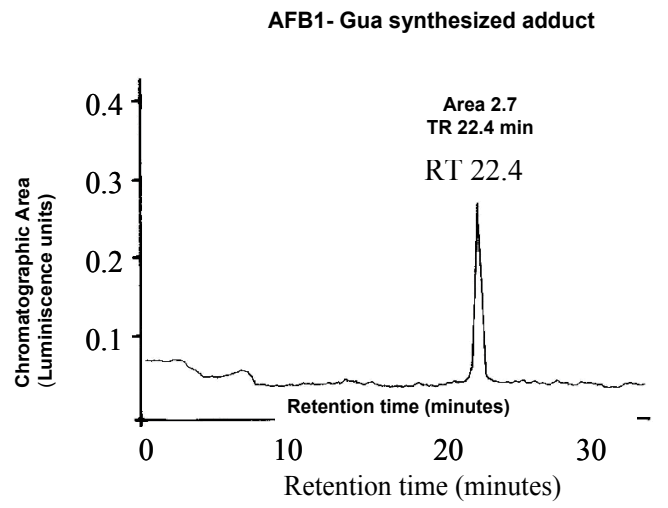

Figure 1: $\quad \mathrm{AFB}_{1}-\mathrm{N}^{7}-\mathrm{Gua}$ adduct synthesized and concentrated by immunoaffinity column. The chromatographic peak at a retention time (RT) of $22.4 \mathrm{~min}$ with a concentration of $2.1 \mathrm{\mu g} / \mathrm{mL}$.

\section{Comparison of HPLC and ELISA methods}

The best inhibition of the $\mathrm{AFB}_{1}$-BSA monoclonal antibody was obtained with a 1:300 concentration from the tissue culture, and the chosen dilution was 1:1000.

An optimal $94 \%$ of inhibition was obtained. ELISA was more sensitive and was able to detect lower concentrations (0.1 ng AF/mg $\mathrm{Cr}$ ) with better recovery of total AFs (AFt) $(38 / 210)$ than the HPLC method (24/210), which could not detect low AF levels in agreement with previous rat and human urine studies [19,34,35].

\section{Analytical quality assurance}

The Costar 3590 plate with a high adherence was chosen for the entire study, and the optimal $\mathrm{AFB}_{1}-\mathrm{Ov}$ coating dilution for ELISA plates was $10 \mathrm{ng}$; the HPLC and ELISA methods showed a 0.95 correlation coefficient and a $>0.90$ with AF concentrations of $>10 \mathrm{ng} / \mathrm{kg}$.

The retention times (RT) in minutes of standards in isocratic HPLC analysis were as follows: $\mathrm{AFB}_{1}-\mathrm{N}^{7}$-Gua adduct (3.9), $\mathrm{AFM}_{1}$ (4.8), AFP (6.1) and $\mathrm{AFB}_{1}$ (7.4), which are all in agreement with previous reports $[29,34]$. Internal HPLC standards confirmed the chromatographic interpretations. The correlation coefficient $\left(R^{2}\right)$ values for the calibration curve for HPLC isocratic analysis were as follows: AFB $\left(\mathrm{R}^{2}=0.999\right) ; \operatorname{AFM}_{1}\left(\mathrm{R}^{2}=0.998\right) ; \mathrm{AFP}_{1}\left(\mathrm{R}^{2}=0.996\right)$; and $\mathrm{AFB}_{1}-\mathrm{N}^{7}-\mathrm{Gua}$ adduct $\left(\mathrm{R}^{2}=0.996\right)$.

\section{Food questionnaire}

Alcoholics experienced behavior problems and memory failures, and did not answer the questionnaire reliably. The standard deviations (SD) for maize, rice, and dairy product consumption were higher for the alcoholics than the other groups, and because these answers were skewed, the same analyses were performed after omitting these answers (Table 1).

The healthy control population ate the same foods as the riskgroups, but they excreted fewer carcinogens; the difference was primarily the ingested amount of each type of food, as shown in Table 2.

\section{Excretion of different AF types in hepatic diseases}

Table 1 shows the frequency of AF positive urine samples, individual percentage frequency, AF types, sex, ranges of positive samples from total $\mathrm{AF}$ concentrations, and $\mathrm{P}$ values. $\mathrm{AFM}_{1}$ is a mutagenic and carcinogenic $[49,50]$ detoxification metabolite of $\mathrm{AFB}_{1}$ and appears with high frequency in all of the risk groups, although its excretion was different $(\mathrm{P} \leq 0.029)$. The VC group had the highest amount of AFM (14-101 ng/mL), AFB 1 (423-502 ng/mL) and AFt (0-4106 ng/cr mg). The HBV group exhibited the second highest of $\mathrm{AFM}_{1}(2-90 \mathrm{ng} / \mathrm{mL})$, $\mathrm{AFB}_{1}(170-324 \mathrm{ng} / \mathrm{mL})$ and AFt $(0.1-1543 \mathrm{ng} / \mathrm{cr} \mathrm{mg})$. The HCV group had the third highest amount of AFM1 (1-44 ng/mL) and AFt (3-60 ng/ cr $\mathrm{mg}$ ) and exhibited no $\mathrm{AFB}_{1}$. In contrast, the healthy control groups had traces of $\mathrm{AFM}_{1}$ (1 to $4 \mathrm{ng} / \mathrm{mL}$ ), no $\mathrm{AFB}_{1}$ and low AFt $(9-42 \mathrm{ng} / \mathrm{cr}$ $\mathrm{mg}$ ). The amounts of AF required to kill dogs and humans via hepatitis have been reported in India [12] to be from 2 to $6 \mathrm{mg}$ of AF daily over a period of a month.

Alcoholics have poor metabolism and thus did not excrete AFM, Patients with HCV and alcoholics did not excrete AFP in urine which was probably eliminated as glucuronide by bile [51]. The frequency and concentration of $\mathrm{AFP}_{1}$ in urine have no relation to dosage-exposition [49] but have been correlated with the development of primary HCC [52]. AFP is excreted as a free compound in urine [49]. 


\begin{tabular}{|c|c|c|c|c|c|c|c|c|c|}
\hline \multirow{2}{*}{ Groups } & \multirow{2}{*}{ Age range } & \multirow{2}{*}{$\begin{array}{l}\% A F+i g / \\
\% A F+\text { tc }\end{array}$} & \multirow{2}{*}{$\begin{array}{c}\text { Sex } \\
\text { fem/masc }\end{array}$} & \multicolumn{4}{|l|}{$\mathbf{T}$} & \multirow{2}{*}{$\begin{array}{c}\text { HPLC } \\
\text { ngAF/mg cr ( } \text { N }^{\circ} \\
+ \text { cases })\end{array}$} & \multirow{2}{*}{$\begin{array}{c}\text { ELISA } \\
\text { ngAF/mg cr } \\
\text { ( } \mathbf{N}^{\circ}+\text { cases) }\end{array}$} \\
\hline & & & & $\mathrm{AFB}_{1}$ & $\mathrm{AFM}_{1}$ & $\mathrm{AFP}_{1}$ & AFB-Gua & & \\
\hline \multicolumn{10}{|c|}{ Risk groups } \\
\hline HBV & $26-68$ & $50 / 7$ & $11 / 19$ & $\begin{array}{c}170-324 \\
\text { (3) }\end{array}$ & $\begin{array}{c}2-90 \\
(4)\end{array}$ & $\begin{array}{c}20-36 \\
(3)\end{array}$ & $\begin{array}{c}1-43 \\
(5)\end{array}$ & $\begin{array}{l}1-590 \\
(6)\end{array}$ & $\begin{array}{c}0.1-1543 \\
(15)\end{array}$ \\
\hline $\mathrm{HCV}$ & $34-64$ & $17 / 2$ & $19 / 11$ & 0 & $\begin{array}{l}1-44 \\
(4)\end{array}$ & 0 & $\begin{array}{c}1-4 \\
(4)\end{array}$ & $\begin{array}{c}2-63 \\
(7)\end{array}$ & $\begin{array}{l}3-60 \\
8)\end{array}$ \\
\hline VC & $30-72$ & $27 / 4$ & $18 / 12$ & $\begin{array}{l}423-502 \\
(2)\end{array}$ & $\begin{array}{c}14-101 \\
(5)\end{array}$ & $\begin{array}{l}48-127 \\
(2)\end{array}$ & $\begin{array}{l}0.4-323 \\
\quad(6)\end{array}$ & $\begin{array}{l}0.3-1693 \\
(11)\end{array}$ & $\begin{array}{c}0-4106 \\
(15)\end{array}$ \\
\hline Range & $26-72$ & $10-50 \%$ & $48 / 42$ & $170-502$ & $1-101$ & $20-127$ & $0.4-323$ & $0.3-1693$ & $0.1-4562$ \\
\hline \multicolumn{4}{|c|}{$\mathrm{N}^{\circ}$ positive cases } & $\begin{array}{l}5 / 210 \\
(2.4 \%)\end{array}$ & $\begin{array}{l}13 / 210 \\
(6.2 \%)\end{array}$ & $\begin{array}{l}5 / 210 \\
(2.4 \%)\end{array}$ & $15 / 210(7.2 \%)$ & $\begin{array}{l}24 / 210 \\
(11.4 \%)\end{array}$ & $\begin{array}{l}38 / 210 \\
(18.1 \%)\end{array}$ \\
\hline \multicolumn{10}{|c|}{ Control groups } \\
\hline $\mathrm{AC}$ & $41-74$ & $10 / 1$ & $10 / 20$ & 0 & 0 & 0 & $\begin{array}{c}1-2 \\
(3)\end{array}$ & $\begin{array}{l}0.3-3 \\
(2)\end{array}$ & $\begin{array}{c}1-10 \\
(3)\end{array}$ \\
\hline $\mathrm{KF}$ & $35-71$ & $3 / 1$ & $17 / 13$ & 0 & 0 & 0 & 0 & 0 & 2 \\
\hline CNHD & $34-69$ & $0 / 0$ & $19 / 11$ & 0 & 0 & 0 & 0 & 0 & 0 \\
\hline $\mathrm{H}$ & $26-72$ & $10 / 1$ & $15 / 15$ & 0 & $\begin{array}{c}1-4 \\
(3)\end{array}$ & $\begin{array}{c}2-3 \\
(2)\end{array}$ & $\begin{array}{c}1 \\
(1)\end{array}$ & $\begin{array}{c}1-10 \\
(4)\end{array}$ & $\begin{array}{c}9-42 \\
(6)\end{array}$ \\
\hline Total & $26-74$ & & $109 / 101$ & & & & & & \\
\hline \multicolumn{4}{|c|}{$\mathrm{N}^{\circ}$ positive cases } & 0 & $3 / 210(1.4 \%)$ & $2 / 210(1.0 \%)$ & $4 / 210(1.9 \%)$ & $6 / 210(2.9 \%)$ & $9 / 210(4.3 \%)$ \\
\hline \multicolumn{10}{|c|}{ Statistical analyses } \\
\hline \multicolumn{4}{|c|}{$P$ value in $F$ test $^{*}$} & 0.036 & 0.0532 & 0.0013 & 0.277 & & \\
\hline \multicolumn{4}{|c|}{$\begin{array}{l}\text { Total number of } 47 \text { positive cases in } 210 \\
\text { total number of samples }\end{array}$} & $\begin{array}{l}5 / 210 \\
(2.4 \%)\end{array}$ & $\begin{array}{c}16 / 210 \\
(76.2 \%)\end{array}$ & $\begin{array}{l}7 / 210 \\
(3.3 \%)\end{array}$ & $\begin{array}{l}19 / 210 \\
(9.1 \%)\end{array}$ & & \\
\hline \multicolumn{4}{|c|}{$P$ values in contrasts ${ }^{a}$} & $\begin{array}{l}\text { VC vs HBV : } \\
0.036\end{array}$ & $\begin{array}{c}\text { VC vs H: } 0.019 \\
\text { VC+HBV+ } \\
\text { HCV vs H: } 0.029\end{array}$ & $\begin{array}{c}\text { VC vs } \mathrm{H}: 0.002 \\
\text { HBV vs } \mathrm{H}: 0.023 \\
\text { VC+HBV vs } \mathrm{H}: 0.0005\end{array}$ & $\begin{array}{l}\text { Non-significant } \\
\text { at } 0.05 \%\end{array}$ & & \\
\hline
\end{tabular}

HBV : Viral B Hepatitis; HCV: Viral C Hepatitis; VC:Viral cirrhosis; AC:Alcoholic cirrhosis; KF:Kidney failure. CNHD: Chronic non hepatic diseases; \% AF + ig/ \% AF + tc total cases: Percentage of aflatoxin positive cases inside the group of 30 , between aflatoxin positive cases inside total 210 cases. ${ }^{*}$ With data previously transformed using Box \& Cox method. a: Always lower averages in Healthy $(\mathrm{H})$. $\left(\mathrm{N}^{\circ}+\right.$ cases): Number of positive cases

Table 1: Excretion of AF types in hepatic diseases, by HPLC and ELISA methods, and statistical analysis.

\begin{tabular}{|c|c|c|c|c|c|c|c|c|c|}
\hline \multirow{4}{*}{ Disease / control } & \multicolumn{9}{|c|}{ Average of food rations reported ingested } \\
\hline & \multicolumn{2}{|c|}{24 and 48 hours reported consumption } & \multicolumn{7}{|c|}{ Annual reported consumption } \\
\hline & \multirow{2}{*}{ Animal products (meats,dairy and eggs) } & \multirow{2}{*}{ Cereals, oil seeds and spices } & \multirow{2}{*}{ Maize } & \multirow{2}{*}{ Wheat } & \multirow{2}{*}{ Rice } & \multirow{2}{*}{ Oil seeds } & \multirow{2}{*}{ Spices } & \multicolumn{2}{|c|}{ Animal products } \\
\hline & & & & & & & & Dairies & Meats \\
\hline HepatitisB virus & 3 & 9 & 1824 & 591 & 186 & 57 & 306 & 748 & 388 \\
\hline Hepatitis $C$ virus & 4 & 6 & 1505 & 584 & 187 & 169 & 354 & 928 & 615 \\
\hline Viral cirrhosis & 4 & 5 & 1466 & 609 & 213 & 108 & 293 & 869 & 402 \\
\hline Healthy cases & 3 & 6 & 1035 & 542 & 145 & 52 & 211 & 582 & 400 \\
\hline
\end{tabular}

Table 2: Average of food rations reported ingested.

The adduct frequency in sick individuals was higher than in the healthy group. This results suggests that $\mathrm{AFB}_{1}-\mathrm{N}^{7}$-Gua adducts are a carcinogenic biomarker in comparison to the other AFs. The correlation of AF content in diseased patients was statistically significant: $\mathrm{P} \leq 0.05$ including alcoholics, and $\mathrm{P} \leq 0.033$ without alcoholics. The differences between viral disease and control groups were highly significant $(\mathrm{P} \leq 0.0002)$, and the presence of virus and AF were correlated. CNHD patients were AF negative, as shown in Table 1. No significant differences were found between AF concentrations in healthy and alcoholic groups compared with the viral disease groups, the differences were significant in the frequency of positive cases.

\section{Relation between diseases and food diets}

The contrasts between groups, the reported food consumption and the AF logarithm are reported in Table 3 . The clusters according the reported food consumption are presented in Table 4.

Cluster 1, associated with the healthy control group, showed low ingestion of all foods. Cluster 3, associated with HBV, showed high consumption of maize, rice, dairy food and low ingestion of wheat, oil seeds and spices. Cluster 7, associated with HCV, showed high consumption of wheat, spices, dairy, an oil seeds, and exhibited an average consumption of other foods. The remaining clusters were not associated with diagnostics.

Cereal, oil seeds and spices (c.os.s.) ingested within the 24 to 48 hours (c.os.s. 24-48) prior to urine sample collection were highly significant $(\mathrm{P} \leq 0.0005)$ as foods with $\mathrm{AF}$ contamination risk in relation to liver diseases. The consumption of maize and derivatives was highly significant $(\mathrm{P} \leq 0.011)$; consumption of oil seeds was also significant $(P \leq 0.019)$. Patients with hepatic viral diseases exhibited a significant difference in the consumption of dairy products $(\mathrm{P} \leq 0.014)$ and of maize $(\mathrm{P} \leq 0.0005)$ and condiments $(\mathrm{P} \leq \mathrm{P} 0.028)$; they also showed a significant difference in AF levels ( $\ln \log _{10}$ transformed) $(\mathrm{P} \leq 0.0009)$ (Table 4). Foods that were most highly associated with liver diseases were maize, oil seeds, and spices, as summarized in Figure 2.

Healthy controls consumed fewer dairy products than the remaining groups $(\mathrm{P} \leq 0.012)$. They also consumed fewer oil seeds, but this was marginally significant $(\mathrm{P} \leq 0.065)$ in relation to the 


\begin{tabular}{|c|c|c|c|c|c|c|c|c|c|c|c|c|}
\hline \multirow{3}{*}{$\begin{array}{l}\text { Variance analysis } \\
\text { followed by contrast test }\end{array}$} & \multicolumn{11}{|c|}{$P$ values per variable in contrast (with alcoholic cirrhosis) } & \multirow{3}{*}{ AF log } \\
\hline & \multicolumn{3}{|c|}{24 and 48 hours consumption } & \multicolumn{8}{|c|}{ Annual consumption } & \\
\hline & Ani & c.os.s. & $\mathrm{OH}$ & Maize & Wheat & Rice & Oil & Spices & Dairy & Meats & [OH] & \\
\hline $\begin{array}{c}\text { VC,AC, HBV,HCV vs KF,CNHD } \\
\& H\end{array}$ & .014 & .524 & 155 & .032 & .390 & .810 & .139 & .105 & .288 & .651 & 0 & .0002 \\
\hline \multirow[t]{2}{*}{$\mathrm{H}$ vs the rest } & .130 & .257 & 365 & .032 & .625 & .09 & .025 & .104 & .029 & .350 & 0 & .0002 \\
\hline & \multicolumn{11}{|c|}{ P values per variable in contrast (without alcoholic cirrhosis) } & \\
\hline VC,HBV\&HCV vs KF,NHD \& H & .014 & .211 & .159 & .0005 & .343 & .279 & .263 & .028 & .146 & .617 & .363 & .0009 \\
\hline $\mathrm{H}$ vs the rest & .106 & .368 & .528 & .109 & .620 & .184 & .065 & .139 & .012 & .368 & .689 & .500 \\
\hline VC vs HBV \& HCV & .463 & .005 & .159 & .400 & .773 & .477 & .874 & .528 & .785 & .225 & .787 & .558 \\
\hline
\end{tabular}

AF log: Aflatoxin logarithm; VC: Viral cirrhosis; HBV: Hepatitis B Virus; HCV: Hepatitis C Virus; C: Controls (AC: Alcoholic cirrhosis; KF: Kidney failure; CNHD: Chronic non hepatic diseases and $\mathrm{H}$ : Healthy groups); Ani: animal derivates; $[\mathrm{OH}]$ :Annual alcohol ingestion; c.os.s.: cereals, oil seeds and spices

Table 3: Contrasts between groups, consumption of food and AF logarithm.

\begin{tabular}{|c|c|c|c|c|c|c|c|c|c|c|c|c|}
\hline \multicolumn{3}{|c|}{ Clusters/groups $^{* *}$} & \multicolumn{10}{|c|}{ Average reported ingested rations } \\
\hline \multirow{2}{*}{$\mathbf{N}^{\circ}$} & \multirow{2}{*}{ Groups* } & \multirow{2}{*}{$\begin{array}{l}\mathrm{N}^{\circ} \text { of } \\
\text { cases }\end{array}$} & \multicolumn{2}{|c|}{$\begin{array}{l}\text { 24-48 hours reported } \\
\text { consumption }\end{array}$} & \multicolumn{8}{|c|}{ Annual reported consumption } \\
\hline & & & $\begin{array}{c}\text { Animal } \\
\text { derivates }\end{array}$ & $\begin{array}{c}\text { Cereals, oilseeds } \\
\text { and spices }\end{array}$ & Maize & Wheat & Rice & $\begin{array}{l}\text { Oil } \\
\text { seeds }\end{array}$ & Spices & Dairy & Meats & {$[\mathrm{OH}]$} \\
\hline 1 & $\mathrm{H}$ & $\begin{array}{l}69 \\
45\end{array}$ & $\begin{array}{l}2 \\
5\end{array}$ & \begin{tabular}{|l|}
6 \\
5 \\
\end{tabular} & $\begin{array}{c}1,106- \\
1,206\end{array}$ & $\begin{array}{c}626 \\
381-\end{array}$ & $\begin{array}{l}162- \\
127-\end{array}$ & $\begin{array}{c}47- \\
52\end{array}$ & $\begin{array}{l}188- \\
177-\end{array}$ & $\begin{array}{l}614- \\
610-\end{array}$ & $\begin{array}{c}354- \\
460\end{array}$ & $\begin{array}{l}0 \\
1\end{array}$ \\
\hline 2 & \multicolumn{12}{|c|}{ Not associated with diagnostics } \\
\hline 3 & HBV & $\begin{array}{c}11 \\
8\end{array}$ & $\begin{array}{l}4 \\
2\end{array}$ & $\begin{array}{c}13 \\
8\end{array}$ & $\begin{array}{l}2,929+ \\
2,888+\end{array}$ & $\begin{array}{l}413 \\
498\end{array}$ & $\begin{array}{c}317+ \\
184\end{array}$ & $\begin{array}{l}70 \\
92\end{array}$ & $\begin{array}{c}169- \\
410\end{array}$ & $\begin{array}{c}1,310+ \\
664-\end{array}$ & $\begin{array}{c}388 \\
317-\end{array}$ & $\begin{array}{c}0 \\
92\end{array}$ \\
\hline $4-6$ & \multicolumn{12}{|c|}{ Not associated with diagnostics } \\
\hline 7 & $\mathrm{HCV}$ & $\begin{array}{l}15 \\
22\end{array}$ & $\begin{array}{l}3 \\
5\end{array}$ & $\begin{array}{l}6 \\
6\end{array}$ & $\begin{array}{l}1,247 \\
1,283\end{array}$ & $\begin{array}{c}875+ \\
704\end{array}$ & $\begin{array}{l}191 \\
164\end{array}$ & $\begin{array}{c}486+ \\
114\end{array}$ & $\begin{array}{l}328 \\
748\end{array}$ & $\begin{array}{c}1,135 \\
1,324+\end{array}$ & $\begin{array}{l}604+ \\
714+\end{array}$ & $\begin{array}{l}2 \\
2\end{array}$ \\
\hline
\end{tabular}

There was no 24-48 hours reported consumption of alcohol; [OH]: Annual reported ingested alcohol; Meats: Meat products and derivates (dairy products and eggs). + Maximum value or near it. -Minimum value or near it. *Diseased/ healthy groups most associated with each cluster, in a correspondence analysis.

** Clusters 4 and 6 were not associated with diagnostics

Table 4: Clusters according food reported consumption.

rest. Compared with the HCV and HBV groups, the VC group was significantly different in the consumption of c.os.s. 24-48 hours prior to urine sample analysis $(\mathrm{P} \leq 0.005)$. A discriminant analysis of three liver diseases and of the healthy control groups showed a correlation between the disease and the ratio of the food consumed (Figure 3).

\section{Discussion}

Humans with chronic HBV and those that are exposed to AFs are more at risk to develop liver cancer, which might be prevented by decreased consumption of AF-contaminated foods [10]

Studies of liver cirrhosis in Mexico have shown the effects rather than the causes of liver disease. $\mathrm{AFB}_{1}-\mathrm{N}^{7}-\mathrm{Gua}$ in urine and $\mathrm{AFB}_{1}-\mathrm{FAPY}$ in tumor adducts are useful molecular biomarkers to determine the etiology of liver diseases, in contrast to agents, such as alcohol, that cause damage and then disappear.

Our results showed a positive association of $\mathrm{AF}$ in the urine of patients with hepatic diseases such as HBV, HCV and VC in agreement with previous reports [53,54]. AF analysis should be included in epidemiological studies [19]. The urine samples from Mexican risk groups had higher levels of AF $(0.12-4106.2 \mathrm{ng} / \mathrm{cr} \mathrm{mg})$ than cases from Africa (0.100-1.0 AF ng/urine $\mathrm{mL}$ ) [55] after measuring units were equalized. Healthy Mexicans had levels of AF five times higher (6.9$33.6 \mathrm{ng} / \mathrm{cr} \mathrm{mg}$ ) than those in the healthy Danish human urine samples (6.5 $\mathrm{AFB}_{1} \mathrm{ng} / \mathrm{cr} \mathrm{mg}$ ), with an increase of $\mathrm{AF}$ excretion when beer was consumed [56]: The amount of maize, hot peppers, spices and eggs consumed in both countries may account for the difference.

$\mathrm{AFB}_{1}$ toxicity is higher than that of its metabolites, but only $10 \%$ was recovered as free $\mathrm{AFB}_{1}$, whereas $90 \%$ was metabolized. Free $\mathrm{AFB}_{1}$, which is not activated, enters and leaves the body without causing major changes and has little impact on diseases, but when it is oxidized, it forms the highly reactive $8,9 \mathrm{AF}$ exo-epoxide, which can bind to DNA, forming the adduct that is the active carcinogen. Metabolic detoxifying processes are glucuronation, sulfonation and acetylation, which produce compounds soluble enough to be excreted and have hydroxylated metabolites as primary substrates of $\mathrm{AFB}_{1}$ (i.e., $\mathrm{AFM}_{1}$, $\mathrm{AFP}_{1}$ and $\left.\mathrm{AFQ}_{1}\right)$, with less toxic and carcinogenic activities $[57,58]$. Free $A F B_{1}$ represents recent exposure (24-48 hours). Ingested amounts of $\mathrm{AFB}_{1}(0.2 \%)$ and $\mathrm{AFB}_{2}(0.6 \%)$ can be calculated when excreted as AFB- $\mathrm{N}^{7}-\mathrm{Gua}$ in urine [37].

$\mathrm{AFB}_{1}-\mathrm{N}^{7}$-Gua adducts, with an average of $31 \mathrm{ng}$, were found to be a biomarker metabolite that was detected in $9 \%$ of the 210 Mexican urine samples, a level inferior to $12.6 \%$ adduct in urine samples reported from Kenya [59] or the excretion of 200 ng adducts with $51 \%$ primary HCC mortality in China [49]. One explanation for this discrepancy is that the use of lime to prepare Mexican tortillas may lower the levels of AF and primary HCC. Excreted AFB-N $\mathrm{N}^{7}-\mathrm{Gua}$ adducts and $\mathrm{AFB}_{1}$ ingestion had a significant correlation of 0.80 and $\mathrm{P}<0.000001$, indicating a close association between exposure and molecular dosimetry [49,53].

The concentration of AF in alcoholics was very low $(0.21 \mathrm{ng} /$ $\mathrm{mL}$ ) because they are an undernourished group; however, in the questionnaire, they said that they ate very well. Unexpectedly, only a single healthy control excreted the adduct $(1.38 \mathrm{ng} / \mathrm{mL})$, but no differences were found between the amounts of adducts from alcoholics and healthy controls. 

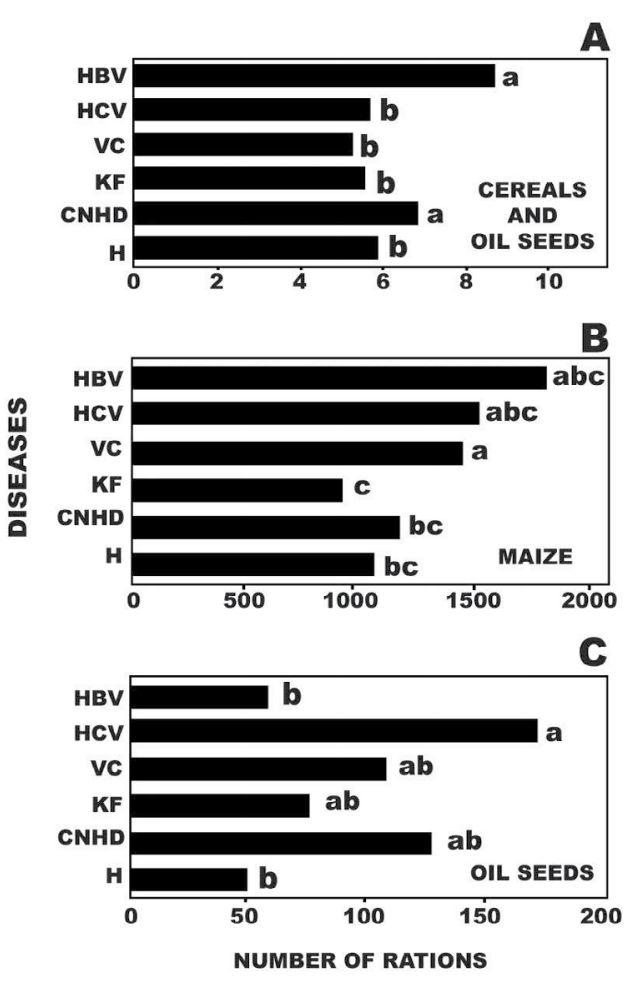

Figure 2: Tukey test from food survey (relation between diseases and number of reported rations). Number of rations: $A$ in 24 to 48 hours; $B$ and $\mathrm{C}$ in a year. Groups with a letter $(\mathrm{a}, \mathrm{b}, \mathrm{c})$ in common are not statistically different, with no common letter are statistically different $(p<0.05)$. Diseases: $\mathrm{HBV}=$ Hepatitis $B$ Virus, HCV=Hepatitis C Virus, VC=Viral cirrhosis, KF= Kidney failure, $\mathrm{CNHD}=$ Chronic non hepatic diseases, $\mathrm{H}=$ Healthy.

\section{ASSOCIATION TENDENCIES}

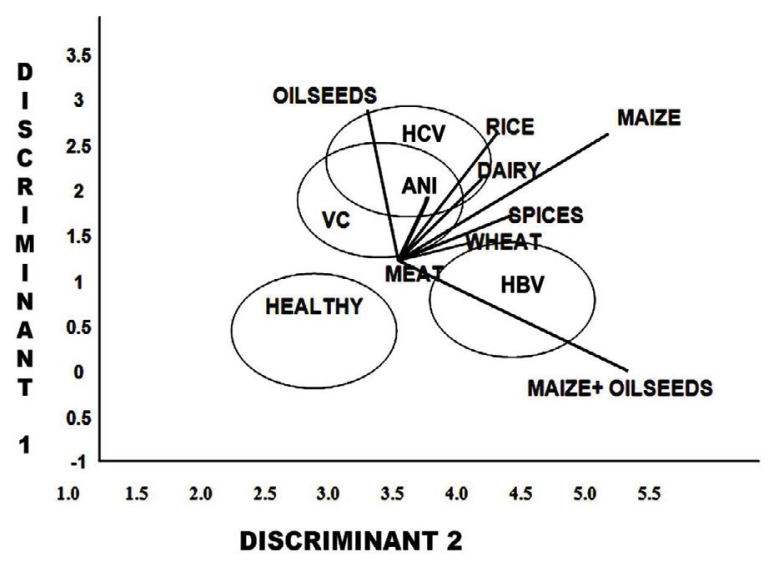

Figure 3: The association shows a circle for each group and axis for each reported food. If a circle is in the direction of an axis, that group has more reported consumption of the food of the axis. The Healthy group was moderated in the reported consumption of all foods; Hepatitis C Virus (HCV) reported to consume more dairies, meats and oil seeds; Viral cirrhosis (VC) more oilseeds; Hepatitis B Virus (HBV) reported to eat more cereals and oil seeds. The food reported consumption of the HCV and VC groups were very similar. Ani=Animal derivates, meat and eggs, were not so significant.
$\mathrm{AFB}_{1}-\mathrm{N}^{7}$-Gua adducts are rapidly formed DNA repair products excreted by the urine, which indirectly indicate the risk of a person developing liver damage or cancer, and are useful biomarkers to determine the role of $\mathrm{AF}$ in chronic liver viral diseases $[60,61]$. The presence of $\mathrm{AFB}_{1}-\mathrm{N}^{7}$-Gua adducts in patient's shows a direct connection with viral infection and suggests an etiopathogenic role of AF toward HCC tumors in countries with high exposure to AF [62-64].

Foods with significant association $(\mathrm{P} \leq 0.0004)$ with liver diseases are maize, oil seeds, spices and dairy derivatives. Patients in the healthy group ingested the same types but a lower amount of these foods and metabolized $\mathrm{AFB}_{1}$ to $\mathrm{AFM}_{1}$ and $\mathrm{AFP}_{1}$; one patient did exhibit adducts but no free $A_{F}$. Risk groups excreted more $A F$ of the following types in diminishing order: $\mathrm{AFB}-\mathrm{N}^{7}-\mathrm{Gua}$ adducts, $\mathrm{AFM}_{1}$ and $\mathrm{AFP}$ metabolites, free $A F B$. AFB- $\mathrm{N}^{7}$-Gua adducts in human urine were confirmed as a molecular biomarker of the risk of developing hepatic diseases by AF, in agreement with other reports [64]. If the food data from 210 patients would have been obtained from chemical analysis, they would have included 42,000 samples from many types of foods and derivatives, and analysis would have been expensive. Thus, we chose to use epidemiological methods to measure human exposure to AFs by dietary questionnaires, and the statistical analysis was accurate, and provided new data in this respect. Aflatoxin exposure biomarkers provide great potential for accurate assessment [65], and food data can explain the origin of the carcinogens; thus, both aspects of this study are complementary.

HCC is associated with HBV chronicity and dietary exposure to aflatoxin, a mutagen targeting codon 249 of the tumor suppressor TP53 (R249S mutation). Complete sequencing of the HBX gene indicated that $R 249 S$ mutations were associated with HCC with no documented prior cirrhosis but not with HCC developing in a context of cirrhosis or in non-cancer chronic liver diseases. Thus, the R249S mutation may specifically cooperate within the $H B X$ gene in a pathway that leads to HCC but bypasses cirrhosis [66].

Exposure to $\mathrm{AFM}_{1}$ can account for a substantial part of the risk of HCC in men with chronic HBV hepatitis and adds to the evidence that HCV and family history of HCC increase the risk of HCC in men with chronic HBV hepatitis [67].

$\mathrm{HCC}$ is related to various etiologies including $\mathrm{HBV}, \mathrm{HCB}$, high alcohol intake, $\mathrm{AFB}_{1}$, dietary exposure to $\mathrm{AF}$ and metabolic syndrome related to genetic and environmental factors. Most of the cases of HCC developed from cirrhosis. Thus, the mechanisms of carcinogenesis and the risk factors cannot be separated from the initiation events leading to cirrhosis. $\mathrm{AFB}_{1}$ and $\mathrm{HBV}$ have a clear direct oncogenic role through point mutations in the TP53 tumor suppressor gene and insertional mutagenesis, respectively. The sequencing and transcriptome analysis will clarify the etiology and genetic events [68].

$\mathrm{AFB}_{1}$ causes HCC, and exposure begins in utero and is lifelong. $\mathrm{AFB}_{1}$ is converted by proteins in the cytochrome $\mathrm{p} 450$ (CYT 450) family into mutagenic and carcinogenic intermediates. $A F B_{1}$ is converted into $\mathrm{AFB}_{1}-8,9$ exo-epoxide, which is in turn converted into $\mathrm{AFB}_{1}-\mathrm{N}^{7}$-Gua adducts. This adduct is metabolized into $\mathrm{AFB}_{1}-\mathrm{FAPY}$ adducts, and these two adducts are mutagenic and carcinogenic. In addition, an arginine to serine mutation at codon 249 of the p53 tumor suppressor gene is produced, abrogating the function of the tumor suppressor gene and contributing to hepatocarcinogenesis. $\mathrm{AFB}_{1}$ acts synergistically with HBV to cause HCC by integrating into the gene and interfering with nucleotide excision repair, activating p21waf1/ cip1, generating DNA mutations, and altering gene methylation. The 
precise pathogenetic mechanisms responsible for $\mathrm{AFB}_{1}$-induced $\mathrm{HCC}$ as well as the interaction between $\mathrm{AFB}_{1}$ and $\mathrm{HVB}$ in causing the tumor are unknown [69].

The AF regulatory standards around the world (4 to $20 \mathrm{ng} / \mathrm{g}$ total $\mathrm{AF}$ ) are not adequately protective for human health, showing a $\mathrm{HCC}$ risk of $>1$ case in 100,000 persons. In contrast, when large amounts of maize and peanuts are consumed and HBV prevalence is high, the protection level is 1 in 10,000 lifetime HCC cases in the population. However, almost all aflatoxin regulations worldwide are adequately protective, with the exception of several nations in Africa and Latin America [70].

In conclusion, studies have reported the link between $\mathrm{HBV}$ and $\mathrm{AF}$, but the present work also shows a link with $\mathrm{AFB}_{1}-\mathrm{N}^{7}$-Gua as a novel biomarker for HBV, HCV and VC and shows that the levels correlate with the type and amount of food ingested. This is one of the most thorough studies of the relationship between AF in foods and hepatic disease; it summarizes 42,000 data points of food rations, detects different $\mathrm{AF}$ and adduct levels in the urine of risk and control groups, and shows their relation to viral hepatic diseases and the importance of $\mathrm{AF}$ adducts as biomarkers in the risk of HCC.

\section{Acknowledgements}

- To Consejo Nacional de Ciencia y Tecnología of Mexico for the PhD scholarship of Maria Teresa Álvarez-Bañuelos.

- Instituto de Biología, Universidad Nacional Autónoma de México (IBUNAM) for the laboratory facilities, technology, equipment and materials that supported this work.

- To Departments of Epidemiology of Social Health, and of Nutriology for their help to structure the food questionnaire and to Gastroenterology consultation for 198 samples, from the "Instituto Nacional de Ciencias Médicas y Nutrición Salvador Zubirán".

- To Hepatic Infectology Dept of the Central Hospital "La Raza" consultation for 12 samples with Hepatitis $B$ virus.

The authors thank to IBUNAM personnel: Noemi Chávez from the Technical Secretary (Secretaría Técnica); Joel Villavicencio, Jorge López, Alfredo Wong, for computer assistance; Julio César Montero and Diana Martínez for design. Finally to Georgina Ortega-Leite and Gerardo Arévalo for library information.

\section{References}

1. Leeson S, Diaz G, Summers J (1995) Poultry metabolic disorders and mycotoxins. University Books, Ontario, Canada.

2. Nakai VK, Rocha LO, Gonçalez E, Fonseca H, Ortega EMM, et al. (2008) Distribution of fungi and aflatoxins in a stored peanuts variety. Food Chem 106: 285-290.

3. Rastogi S, Das M, Khanna SK (2001) Quantitative determination of aflatoxin B1-oxime by column liquid chromatography with ultraviolet detection. J Chromatogr A 933: 91-97.

4. Kurtzman CP, Horn BW, Hesseltine CW (1987) Aspergillus nomius, a new aflatoxin-producing species related to Aspergillus flavus and Aspergillus tamarii. A Van Leeuwenhoek 53: 147-158.

5. Blesa J, Soriano JM, Molto JC, Manes J (2004) Limited survey for the presence of aflatoxins in foods from local markets and supermarkets in Valencia, Spain. Food Addit Contam 21: 165-171.

6. Goto T, Wicklow DT, Ito Y (1996) Aflatoxin and cyclopiazonic acid production by a sclerotium-producing A.tamarii strain. Appl Environ Microbiol 62: 40364038.

7. Bbosa GS, Kitya D, Odda J, Ogwal-Okeng J (2013) Aflatoxins metabolism, effects on epigenetic mechanisms and their role in carcinogenesis. Health 5 : 14-34.

8. Reddy SV, Waliyar F (2012) Properties of aflatoxin and its producing fungi: Aflatoxins, 2012.

9. Domsch KH, Gams W, Anderson TH (1980) Compendium of soil fungi.
Academic Press, England, London.

10. Kensler TW, Roebuck BD, Wogan GN, Groopman JD (2010) Aflatoxin: A 50Year odyssey of mechanistic and translational toxicology. Toxicol Sci 120 S28-S48.

11. Olsen JH, Dragsted I, Autrup H (1988) Cancer risk and occupational exposure to aflatoxins in Denmark. Brit J Cancer 58: 392-396.

12. Krishnamachari KA, Bhat RV, Naragajan V, Tilak TB (1975) Hepatitis due to aflatoxicosis. An outbreak in Western India. Lancet 1: 1061-1063.

13. Alter MJ (1993) The detection, transmission, and outcome of hepatitis $C$ virus infection. Infect Agent Dis 2: 155-166.

14. Yadgiri B, Reddy V, Tulpule PG, Srikantia SG, Gopalan C (1970) Aflatoxin and Indian childhood cirrhosis. Am J Clin Nutr 23: 94-98.

15. Méndez-Sánchez N, Aguilar-Ramírez JR, Reyes A, Dehesa M, Juárez A, et al (2004) Etiology of liver cirrhosis in Mexico. Ann Hepatol 3: 30-33.

16. Harrison JC, Carvajal M, Garner RC (1993) Does aflatoxin exposure in the United Kingdom constitute a cancer risk? Environ Health Perspect 99: 99-105.

17. Carvajal M, Berumen J, Guardado-Estrada M (2012). The presence of AFB1FAPY adduct and human papilloma virus in cervical smears from cancer patients in Mexico. Food Addit Contam 29: 258-268.

18. Staib F, Hussain SP, Hofseth LJ, Wang XW, Harris CC (2003) TP53 and liver carcinogenesis. Hum Mutat 21: 201-216.

19. Wild CP, Jansen LAM, Cova L, Montesano R (1993) Molecular dosimetry of aflatoxin exposure: contribution to understanding the multifactorial etiopathogenesis of primary hepatocellular carcinoma with particular reference to hepatitis B virus. Environ Health Perspect 99: 115-122.

20. Llewelyn GS, Stepheson GA, Hoffman JW (1977) AFB1 induced toxicity and teratogenicity in Japanese Medaka eggs (Oryzias latipes). Toxicon 15: 582-587.

21. Pestka JJ, Bondy GS (1994) Mycotoxin-induced immune modulation Immunotoxicology and Immunopharmacology, Raven Press, New York, USA pp. 163-182.

22. Pier AC, McLoughlin ME (1985) Mycotoxin supression of immunity. In Trichothecenes and other mycotoxins. John Wiley and Sons Ltd. 507-519.

23. Gong Y, Hounsa A, Egal S, Turner PC, Sutcliffe AE, Hall AJ, Cardwell K, Wild CP (2004) Postweaning exposure to aflatoxin results in impaired child growth: a longitudinal study en Benin, West Africa. Environ Health Perspect 112: 13341338.

24. Schwartzbord J, Brown DL, Pape JW, Verdier RI, Filbert ME, et al. (2014) Aflatoxin-Lysine Adducts in Haitian Patients Ingesting Peanut and Maize Products. J Hunger Environ Nutr 9: 244-255.

25. Al-Hammadi S, Marzouqi F, Al-Mansouri A, Shahin A, Al-Shamsi M, et al (2014) The cytotoxicity of aflatoxin B1 in human lymphocytes. Sultan Qaboos Univ Med J 14: e65.

26. Lillehoj EB (1987) The Aflatoxin -In-Maize Problem: The Historical Perspectiva. Chapter 3. In: Aflatoxin in Maize: A proceedings of the workshop. CIMMYT Mexico, D.F.

27. Aguirre Botello M, (2015) Mexico, main causes of mortality since 1938 Accessed August 5, 2015

28. Meléndez N, González M, Almazán J, Marín E, Lisker M, et al. (1992) Historia natural del carcinoma hepatocelular en el Instituto Nacional de la Nutrición. Rev Gastroenterol Méx 57: 277-278.

29. Essigmann JM, Croy RG, Nadzan AM, Busby WF, Reinhold VN, et al. (1977) Structural identification of the major DNA adduct formed by aflatoxin B1 in vitro. P Natl Acad Sci USA 74: 1870-1874.

30. Yu FL, Render W, Geronimo IH (1990) Base and sequence specificities of aflatoxin B1 binding to single and double stranded DNAs. Carcinogenesis 11: 475478.

31. Yang SS, Taub JV, Modali R, Vieira W, Yasei P, et al. (1985) Dose dependency of aflatoxin B1 binding on human high molecular weight DNA in the activation of proto-oncogene. Environ Health Persp 62: 231-238.

32. Aydın M, Aydin S, Bacanlı M, Başaran N (2015) Aflatoxin levels in patients with chronic B hepatitis with cirrhosis or hepatocellular carcinoma in Balikesir, Turkey. J Viral Hepatitis. 
Citation: Alvarez-Banuelos MT, Carvajal-Moreno M, Mendez-Ramirez I, Rojo-Callejas F (2015) Free and DNA Adducted Aflatoxins in Chronic Liver Diseases that Predispose Patients to Hepatocellular Carcinoma in Mexico. J Cancer Sci Ther 7: 274-282. doi:10.4172/1948-5956.1000363

33. Van Rensburg SJ, Van Der Watt JJ, Purchase IFH, Pereira Coutinho L, Markham RS (1974) Primary liver cancer rate and aflatoxin intake in high cancer area. S Afr Med J 48: 2508 a-d.

34. Álvarez MT, Carvajal M, Rojo F, Escobar A (1999) Comparison between inhibitory indirect ELISA and HPLC methods to quantify free and adducted aflatoxins in human urine. Nat Toxins 7: 139-145

35. Harrison JC, Carvajal M, Garner RC (1991) Immunological detection of AFB1DNA and AFB1-serum albumin adducts in rat and human tissues. In: Human Carcinogen Exposure: Biomonitoring and Risk Assessment. Oxford University Press. Oxford, UK

36. Martin CN, Garner RC (1977) Aflatoxin-B oxide generated by chemical or enzymatic oxidation of aflatoxin B1 causes guanine substitution in nucleic acids. Nature 267: 863-865.

37. Groopman JD, Haugen A, Goodrich GR, Wogan GN, Harris CC (1982) Quantitation of aflatoxin B1 modified DNA using monoclonal antibodies. Cancer Res 42: 3120-3124.

38. Swenson DM, Miller JA, Miller EC (1975) The reactivity and carcinogenicity of aflatoxin B1-2,3-dichloride, a model of the putative 2,3-oxide metabolite of aflatoxin B1. Cancer Res 35: 3811-3823.

39. Hair JF, Anderson RE, Tatham, RL, Black WC (1995) Multidimensional scaling In: Multivariate data analysis. Prentice Hall, Englewood Cliffs, New Jersey, USA.

40. Horwitz W (1982) Evaluation of analytical methods used for regulations of foods and drugs. Anal Chem 54: 67A-76A

41. Horwitz W (1995) Protocol for the design, conduct and interpretation of methodperformance studies. Pure Appl Chem 67: 331-343.

42. Thompson M (2000) Towards a unified model of errors in analytical measurement. Analyst 125: 2020-2025.

43. Thompson M, Wood R (1995) Harmonized guidelines for internal quality control in analytical chemistry laboratories. Pure Appl Chem 67: 649-666.

44. García MA, Alcántara A (2002) Validation guide of analytical methods. Ed. National College of Pharmaco-Biologist Chemists, AC. DF Mexico 1-122.

45. Thompson M, Ellison SLR, Fajgelj A, Willetts P, Wood R (1999) Harmonised guidelines for the use of recovery information in analytical measurement. Pure Appl Chem 71: 337-348.

46. AOAC [Association of Official Analytical Chemist International] (2005) Natural toxins. Chapter 49: 1-99. Official Methods of Analysis of AOAC International. Maryland, USA.

47. Wood GM, Mann PJ (1987) Evaluation of total aflatoxin EASI-EXTRACT TM columns for the analysis of aflatoxins in peanuts. Technical Note No 63 Leather-head Food Research Association (UK).

48. Goto T (1990) Comparison of some immunological aflatoxin analysis methods Rep Nat Food Res Inst 54: 35-43.

49. Groopman JD, Zhu JQ, Donahue PR, Pikul A, Zhang LS, et al. (1992) Molecula dosimetry of urinary aflatoxin-DNA adducts in people living in Guangxi autonomous region, People's Republic of China. Cancer Res 52: 45-52.

50. Cullen JM, Ruebner BH, Hseih LS, Hyde DM, Hseih DP (1987) Carcinogenicity of dietary aflatoxin M1 in male Fisher rats compared to aflatoxin B1. Cancer Res 47: 1913-1917.

51. Holeski CJ, Eaton DL, Monroe DH, Bellamy GM (1987) Effects of phenobarbital on the biliary excretion of aflatoxin P1-Glucuronide and aflatoxin B1-Sglutathione in the rat. Xenobiotica 17: 139-153.

52. Kirby GM, Wolf CR, Neal GE, Judah DJ, Henderson CJ, et al. (1993) In vitro metabolism of aflatoxin B1 by normal and tumourous liver tissues from Thailand. Carcinogenesis 14: 2613-2620.

53. Groopman JD, Sabbioni G, Wild CP (1991) Molecular dosimetry of human aflatoxin exposure. Chapter 17 . In: Molecular dosimetry and Human cancer: Analytical, Epidemiological and Social considerations. CRC Press. Boston, USA.

54. Autrup H, Bradley KA, Shamsuddin AKM, Wakhisi J, Wasunna A (1983) A detection of putative adduct with fluorescence characteristics identical to 2,3-dihydro-2-(7'-guanyl)-3-hydroxyaflatoxin B1 in human urine collected in Murangá District, Kenya. Carcinogenesis 4: 1193-1195.

55. Wild CP, Chapot B, Scherer E, Den Engelse L, Montesano R (1988) The application of antibody methodologies to the detection of aflatoxin in human body fluids. In: Methods for Detecting DNA Damaging Agents in Humans: Applications in Cancer Epidemiology and Prevention. IARC Sci Publ 89: 67-74.

56. Dragsted LO, Bull I, Autrup H (1988) Substances with affinity to a monoclonal aflatoxin B1 antibody in Danish urine samples. Food Chem Toxicol 26: 233 242

57. Hayes JD, Judah DJ, McLellan LI, Neal GE (1991) Contribution of the glutathione S-transferases to the mechanisms of resistance to aflatoxin B1. Pharmacol Therapeut 50: 443-472.

58. Neal GE (1995) Genetic implications in the metabolism and toxicity of mycotoxins. Toxicol Lett 82/83: 861-867.

59. Autrup H, Bradley KA, Shamsuddin AKM, Wakhisi J, Wasunna A (1983) A detection of putative adduct with fluorescence characteristics identical to 2,3-dihydro-2-(7'-guanyl)-3-hydroxyaflatoxin B1 in human urine collected in Murangá District, Kenya. Carcinogenesis (Lond.) 4: 1193-1195.

60. Wright AS (1991) Emerging strategies for the determination of human carcinogens: detection, identification, exposure monitoring, and risk evaluation. In: Human Carcinogen Exposure: Biomonitoring and Risk Assessment. Oxford University Press, Oxford, UK.

61. Bennett RA, Essigmann JM, Wogan GN (1981) Excretion of an aflatoxinguanine adduct in the urine of AFB1-treated rats. Cancer Res 41: 650-654.

62. Hsieh DPH, Atkinson DN (1995) Recent aflatoxin exposure and mutation at codon 249 of the human p53 gene: lack of association. Food Addit Contam 12: $421-424$.

63. Groopman JD, Wogan GN, Roebuck BD, Kensler TW (1994) Molecular biomarkers for aflatoxins and their application to human cancer prevention. Cancer Research Suppl 54: 1907s-1911s.

64. Groopman JD, Kensler TW, Wild CP (2008) Aflatoxin, Hepatitis B Virus and Liver Cancer: A Paradigm for Molecular Epidemiology. Molecular Epidemiology of Chronic Diseases, Wiley \& Sons, Ltd.

65. Wild CP, Turner PC (2002) The toxicology of aflatoxins as a basis for public health decisions. Mutagenesis 17: 471-481.

66. Ortiz-Cuaran S, Villar S, Gouas D, Ferro G, Plymoth A, et al. (2013) Association between HBX status, aflatoxin-induced R249S TP53 mutation and risk of hepatocellular carcinoma in a case-control study from Thailand. Cancer Lett 331: 46-51.

67. ZongTang S, PeiXin L, Gail MH, Pee D, QiNan Z, et al. (1999) Increased risk of hepatocellular carcinoma in male hepatitis $B$ surface antigen carriers with chronic hepatitis who have detectable urinary aflatoxin metabolite M1. Hepatology (Baltimore) 30: 379-383

68. Nault JC (2014) Pathogenesis of hepatocellular carcinoma according to aetiology. Best Pract Res Clin Gastroenterol 28: 937-947.

69. Kew MC (2013) Aflatoxins as a cause of hepatocellular carcinoma. J Gastrointestin Liver Dis 22: $305-310$.

70. Wu F, Stacy SL, Kensler TW (2013) Global risk assessment of aflatoxins in maize and peanuts: are regulatory standards adequately protective? J Toxicol Sci 135: 251-259. 